\title{
Study of subchronic toxicity of the developed antibacterial drug based on exosomal particles
}

\author{
Elena Kastarnova ${ }^{1, *}$, Vladimir Orobets ${ }^{1}$, Valeria Shahova ${ }^{1}$, Olga Sevostyanova ${ }^{1}$, Ilya \\ Belyaev $^{2}$, and Elena Grudeva ${ }^{1}$ \\ ${ }^{1}$ The Stavropol State Agrarian University, 12, Zootechnichesky lane, 357017, Stavropol, Russian \\ ${ }^{2}$ The Stavropol State Medical University, 310, Mira str., Stavropol, 355017, Russia
}

\begin{abstract}
One of the main promising directions in the development of pharmacology is the development of drugs that provide targeted drug concentration and effective approaches to obtaining them using nanoscale drug delivery systems. In our opinion, the most promising is the use of biodegradable delivery systems due to their low toxicity and xenobiotic effects on the patient's body. The need to develop regulated drug delivery systems is due to their clear advantage over analogues in standardized dosage forms. Based on modern research publications we have developed an exosomal antibacterial form of azithromycin that has pronounced selective properties for respiratory epithelial cells. The aim of the work was to study the safety parameters of the developed drug based on exosomal particles, in particular subchronic toxicity. For the study 3 experimental and 1 control groups of white rats weighing 190-220 g were formed with 10 heads each. The drug was administered intragastrically daily for 90 days in doses of $1 / 10 ; 1 / 20$ and $1 / 50$ of the LD50 set in the acute experiment. The study found that the use of the developed exosomal drug intragastrically once a day for 90 days does not affect the behavioral responses of animals and their external condition.
\end{abstract}

\section{Introduction}

Progress in the development of new drugs is largely related to the production of fundamentally new drug forms. In this aspect, biopharmaceutical research is aimed at creating a new generation of drugs based on delivery devices that provide targeted concentration of the drug in the area of the pathological process in the necessary therapeutic concentration and reduce the adverse effects on the body of toxic compounds, which allows to extend the life of existing drugs and most fully realize their capabilities. At the moment, researchers are working on the design and improvement of artificial vectors, the main problem of which is insufficient focus, not studied biocompatibility, labor intensity, high cost of production and, as a result, expensive drugs. In our opinion, the most promising is the use of biodegradable delivery systems, due to their low toxicity and xenobiotic effects on the patient's body $[1,2,3]$. The development of biocompatible nanostructured drugs is an integral part of modern veterinary medicine [4-8]. The need to develop regulated drug

* Corresponding author: elena-kastarnova@mail.ru 
delivery systems is conditioned by their clear therapeutic advantage over analogues in standardized dosage forms [9-13]. Based on modern research publications we have developed an exosomal antibacterial form of azithromycin that has pronounced selective properties for respiratory epithelial cells $[14,15,16]$. The aim of the work was to study the safety parameters of the developed drug based on exosomal particles, in particular subchronic toxicity.

\section{Materials and methods}

The research was carried out on the basis of the vivarium of the Therapy and Pharmacology Department of the Veterinary Medicine Faculty of the Stavropol State Agrarian University. White Wistar rats were used as experimental animals to study the subchronic toxicity of the resulting liposomal drug on the body. The supplier of laboratory animals provided documents indicating the last control of the state of animal health. Rats had not previously participated in experiments. The animals were placed in a quarantine and adaptation section for 14 days. During this period, a daily inspection of the external condition of the animals was carried out. Animals with abnormalities detected during the inspection were not included in the experimental groups. After the quarantine period, the animals were transferred to the vivarium's experimental hall. Rats were kept in polycarbonate cages covered with steel lattice covers with a feed recess, 5 heads each. Sawdust served as the bedding. The animals were fed ad libitum a full-fledged extruded feed for laboratory animals. The temperature and humidity in the experimental and quarantine sections of the vivarium were monitored daily using psychrometric VIT-2 hygrometers (verification certificates dated 12.2018). Microclimate parameters were registered manually. The temperature and humidity regime was within the normal range: air temperature $-20-26^{\circ} \mathrm{C}$; relative humidity $-30-70 \%$. Experimental rats were randomly assigned to groups. The body weight was taken as a criterion, so that the individual weight value did not deviate from the average by more than $10 \%$ (scales V11P3. e $=0.0005 \mathrm{~kg}$. OHAUS CORPORATION. USA. Свидетельство о поверке № 28/124). Each animal was assigned an individual number placed on the coat. The cells were labeled with the study code, breed, sex, and animal group.

For the study, 3 experimental and 1 control group of white rats weighing 190-220 g with 10 heads each ( 5 females and 5 males) were formed. The drug was administered intragastrically daily for 90 days in doses of $1 / 10 ; 1 / 20$ and $1 / 50$ of the LD50 set in the acute experiment. During the entire period of research, general condition and behavior of animals were observed, as well as their reaction to stimuli (sound, light), symptoms of intoxication, and possible death. On the 1st day after the last administration of the drug, 5 rats from each group were subjected to euthanasia followed by morphological and biochemical blood tests, a pathoanatomic autopsy with a macroscopic description of organs and tissues, and determination of mass coefficients of rat organs (liver, heart, spleen, lungs, and kidneys). After 10 days after the last administration of the drug, the remaining 5 rats from each group were euthanized, followed by morphological and biochemical blood tests, a pathoanatomic autopsy with a macroscopic description of organs and tissues, and determination of mass coefficients of rat organs (liver, heart, spleen, lungs, and kidneys) to determine the reversibility of processes after repeated intragastric administration of the drug. Statistical processing was performed on Student-Fisher method using the t-test.

\section{Results and discussion}


When studying subchronic toxicity in rats, it was found that repeated use of drugs in all tested doses did not cause significant changes in the clinical state of white rats. Behavioral responses, feed intake and water consumption and respiratory rate in all animals of the experimental groups remained within the normal range and did not differ from the control. During the follow-up period, no digestive or urinary disorders were detected in the rats. There were no cases of death among animals during the experiment. The animals willingly ate food, and gradually gained weight. There were no significant differences in this indicator during the experiment. There was no dependence on the dosage level of the drug (table 1).

Table 1. Dynamics of body weight gain in white Wistar rats after repeated use of exosomal drug.

\begin{tabular}{|c|c|c|c|c|}
\hline \multirow{2}{*}{$\begin{array}{c}\text { Animal } \\
\text { group. } \\
\text { dose. } \\
\mathbf{m g} / \mathbf{~ k g}\end{array}$} & Initial & $\mathbf{2 4}$ days & $\mathbf{4 5}$ days & $\mathbf{9 0}$ days \\
\cline { 2 - 5 } & $195.2 \pm 2.22$ & $204.9 \pm 3.45$ & $215.6 \pm 5.47$ & $227.4 \pm 6.38$ \\
\hline $\begin{array}{c}\text { Control } \\
\text { 1/10 from } \\
\text { LD50 }\end{array}$ & $194.8 \pm 3.73$ & $206.2 \pm 3.77$ & $214.5 \pm 6.37$ & $226.2 \pm 7.01$ \\
\hline $\begin{array}{c}1 / 20 \text { from } \\
\text { LD50 }\end{array}$ & $193.2 \pm 2.21$ & $204.6 \pm 4.63$ & $215.2 \pm 5.76$ & $228.5 \pm 7.72$ \\
\hline $\begin{array}{c}1 / 50 \text { from } \\
\text { LD50 }\end{array}$ & $197.0 \pm 1.24$ & $209.5 \pm 3.62$ & $217.3 \pm 6.26$ & $229.4 \pm 7.38$ \\
\hline
\end{tabular}

Where: *- $\mathrm{p} \leq 0.05$ - the difference is statistically significant in comparison with the indicators of the control group.

When evaluating the effect of the test drug on the functional state of the Central nervous system (CNS), it was noted that the rats retained motor activity comparable to that of control group animals. Experimental rats responded to external stimuli adequately. The results of hematological analysis of peripheral blood of rats in 1 day and 10 days after the last injection showed, that the number of erythrocytes, red blood cells, white blood cells and leukogram did not change significantly and ranged from control values (Tables 2-3). All minor changes found in the hematological picture of the blood of experimental rats corresponded to the reference values for this animals.

Table 2. Exosomal drug effect on blood hematological parameters in white Wistar rats, 1 day after the last administration of the drug.

\begin{tabular}{|c|c|c|c|c|c|}
\hline \multirow{2}{*}{\multicolumn{2}{|c|}{ Indicators }} & \multicolumn{4}{|c|}{ Animal group. dose. $\mathrm{mg}$ / kg } \\
\hline & & Control & $\begin{array}{l}\text { 1/10 from } \\
\text { LD50 }\end{array}$ & $\begin{array}{l}\text { 1/20 from } \\
\text { LD50 }\end{array}$ & $\begin{array}{l}\text { 1/50 from } \\
\text { LD50 }\end{array}$ \\
\hline \multicolumn{2}{|c|}{ Red blood cells. $10^{12} / \mathrm{L}$} & $7.46 \pm 0.23$ & $7.61 \pm 0.25$ & $7.52 \pm 0.17$ & $7.41 \pm 0.16$ \\
\hline \multicolumn{2}{|c|}{ Mean Cell Volume (MCV). $\mathrm{mcm}^{3}$} & $53.6 \pm 0.77$ & $54.6 \pm 0.61$ & $53.1 \pm 0.48$ & $53.1 \pm 0.48$ \\
\hline \multicolumn{2}{|c|}{$\begin{array}{l}\text { Mean concentration hemoglobin } \\
(\mathrm{MCH}) . \mathrm{Hb}\end{array}$} & $18.3 \pm 0.39$ & $18.0 \pm 0.49$ & $18.3 \pm 0.22$ & $18.4 \pm 0.29$ \\
\hline \multicolumn{2}{|c|}{$\begin{array}{l}\text { Mean corpuscular hemoglobin } \\
\text { concentration (MCHC). g/dL }\end{array}$} & $34.1 \pm 0.27$ & $34.5 \pm 0.61$ & $34.7 \pm 0.28$ & $34.2 \pm 0.33$ \\
\hline \multicolumn{2}{|l|}{ Hemoglobin. g/l } & $130.1 \pm 2.23$ & $127.3 \pm 5.17$ & $128.6 \pm 1.74$ & $129.2 \pm 1.69$ \\
\hline \multicolumn{2}{|l|}{ Hematocrit. \% } & $43.5 \pm 0.53$ & $41.1 \pm 1.43$ & $41.1 \pm 0.53$ & $41.4 \pm 0.47$ \\
\hline \multicolumn{2}{|c|}{ Thrombocyte. $10^{9} / 1$} & $617.5 \pm 13.4$ & $613.9 \pm 21.2$ & $593.5 \pm 26.3$ & $614.2 \pm 21.6$ \\
\hline \multicolumn{2}{|c|}{ White blood cells. $10^{9} / 1$} & $7.01 \pm 0.26$ & $6.91 \pm 0.25$ & $7.14 \pm 0.31$ & $7.25 \pm 0.23$ \\
\hline \multirow{3}{*}{ Neutrophils. \% } & young & 0 & 0 & 0 & 0 \\
\hline & rod-core & $0.39 \pm 0.03$ & $0.32 \pm 0.09$ & $0.37 \pm 0.08$ & $0.29 \pm 0.08$ \\
\hline & segmentonuclear & $15.8 \pm 1.37$ & $14.1 \pm 0.69$ & $15.4 \pm 1.41$ & $14.6 \pm 1.38$ \\
\hline \multicolumn{2}{|l|}{ Basophils. \% } & 0 & 0 & 0 & 0 \\
\hline \multicolumn{2}{|l|}{ Eosinophils. \% } & $2.37 \pm 0.23$ & $2.46 \pm 0.39$ & $2.43 \pm 0.33$ & $2.37 \pm 0.42$ \\
\hline
\end{tabular}




\begin{tabular}{|l|l|l|l|l|}
\hline Monocytes. \% & $2.35 \pm 0.39$ & $2.41 \pm 0.26$ & $2.59 \pm 0.43$ & $2.39 \pm 0.38$ \\
\hline Lymphocytes. \% & $79.1 \pm 1.69$ & $80.1 \pm 1.49$ & $79.8 \pm 1.51$ & $81.4 \pm 1.94$ \\
\hline
\end{tabular}

Where: * $*_{-} \leq 0.05$ - the difference is statistically significant in comparison with the indicators of the control group.

Table 3. Exosomal drug effect on blood hematological parameters in white Wistar rats, 10 days after the last administration of the drug.

\begin{tabular}{|c|c|c|c|c|c|}
\hline \multirow{2}{*}{\multicolumn{2}{|c|}{ Indicators }} & \multicolumn{4}{|c|}{ Animal group. dose. $\mathrm{mg} / \mathrm{kg}$} \\
\hline & & Control & $\begin{array}{l}\text { 1/10 from } \\
\text { LD50 }\end{array}$ & $\begin{array}{l}\text { 1/20 from } \\
\text { LD50 }\end{array}$ & $1 / 50$ from $L D 50$ \\
\hline \multicolumn{2}{|r|}{ Red blood cells. $10^{12} / \mathrm{L}$} & $7.78 \pm 0.20$ & $7.68 \pm 0.27$ & $7.54 \pm 0.33$ & $7.75 \pm 0.49$ \\
\hline \multicolumn{2}{|r|}{ Mean Cell Volume (MCV). $\mathrm{mcm}^{3}$} & $53.1 \pm 1.12$ & $52.3 \pm 1.05$ & $52.4 \pm 0.49$ & $52.9 \pm 0.61$ \\
\hline \multicolumn{2}{|r|}{$\begin{array}{l}\text { Mean concentration hemoglobin } \\
(\mathrm{MCH}) . \mathrm{Hb}\end{array}$} & $17.9 \pm 0.45$ & $17.9 \pm 0.34$ & $17.7 \pm 0.54$ & $17.7 \pm 0.49$ \\
\hline \multicolumn{2}{|r|}{$\begin{array}{l}\text { Mean corpuscular hemoglobin } \\
\text { concentration (MCHC). g/dL }\end{array}$} & $32.1 \pm 0.37$ & $31.2 \pm 0.48$ & $31.9 \pm 0.57$ & $31.4 \pm 0.38$ \\
\hline \multicolumn{2}{|r|}{ Hemoglobin. g/l } & $128.4 \pm 1.46$ & $126.3 \pm 1.56$ & $127.9 \pm 5.13$ & $128.6 \pm 1.83$ \\
\hline \multicolumn{2}{|c|}{ Hematocrit. \% } & $40.1 \pm 0.39$ & $39.6 \pm 0.40$ & $40.5 \pm 0.77$ & $40.9 \pm 0.35$ \\
\hline \multicolumn{2}{|c|}{ Thrombocyte. $10^{9} / 1$} & $628.3 \pm 14.9$ & $621.3 \pm 17.8$ & $624.3 \pm 27.7$ & $623.6 \pm 36.1$ \\
\hline \multicolumn{2}{|c|}{ White blood cells. $10^{9} / 1$} & $7.21 \pm 0.24$ & $7.34 \pm 0.2$ & $7.18 \pm 0.31$ & $6.98 \pm 0.28$ \\
\hline \multirow{7}{*}{ 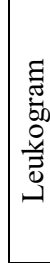 } & \multirow{4}{*}{\begin{tabular}{ll} 
Neutrophils.\% & rod-core \\
\cline { 2 - 2 } & segmentonuclear \\
Basophils. \% &
\end{tabular}} & 0 & 0 & 0 & 0 \\
\hline & & $0.69 \pm 0.27$ & $0.52 \pm 0.14$ & $0.65 \pm 0.18$ & $0.57 \pm 0.13$ \\
\hline & & $14.5 \pm 0.79$ & $14.8 \pm 0.84$ & $14.6 \pm 1.15$ & $13.9 \pm 1.17$ \\
\hline & & 0 & 0 & 0 & 0 \\
\hline & Eosinophils. \% & $3.26 \pm 0.29$ & $3.49 \pm 0.35$ & $3.19 \pm 0.57$ & $3.36 \pm 0.20$ \\
\hline & Monocytes. \% & $2.63 \pm 0.39$ & $2.71 \pm 0.36$ & $2.96 \pm 0.61$ & $2.87 \pm 0.36$ \\
\hline & Lymphocytes. \% & $81.1 \pm 1.06$ & $79.8 \pm 1.01$ & $79.8 \pm 2.06$ & $80.3 \pm 1.18$ \\
\hline
\end{tabular}

Where: *- $\mathrm{p} \leq 0.05$ - the difference is statistically significant in comparison with the indicators of the control group.

As can be seen from the data of blood biochemical parameters, no significant changes were observed in the experimental group animals when compared with similar indicators in the control group animals (Table 4). There were no pathological changes in the values of indicators that characterize the protein synthesis function of the liver-the concentration of crude protein and albumin. The level of fermentemia, both aminotransferases underwent minor fluctuations in the range taken as a conditional norm for this animals, which confirms the absence of cytolysis processes activation. Thus, it can be concluded that the developed exosomal drug in the tested dose range does not have a negative effect on the functional state of the liver.

Table 4. Exosomal drug effect on blood biochemical parameters in white Wistar rats.

\begin{tabular}{|l|c|c|c|c|}
\hline \multicolumn{5}{|c|}{$\mathbf{2 4}$ hours after the last injection } \\
\hline \multirow{2}{*}{ Indicators } & \multicolumn{4}{|c|}{ Animal group. dose. mg / kg } \\
\cline { 2 - 5 } & Control & $\mathbf{1 / 1 0}$ from LD50 & $\mathbf{1 / 2 0}$ from LD50 & $\mathbf{1 / 5 0}$ from LD50 \\
\hline Crude protein. g/l & $65.2 \pm 2.17$ & $61.7 \pm 2.14$ & $62.5 \pm 2.11$ & $62.4 \pm 2.14$ \\
\hline AsAT. U/1 & $157.7 \pm 29.2$ & $167.7 \pm 29.1$ & $169.9 \pm 28.8$ & $165.3 \pm 27.6$ \\
\hline AlAT. U/1 & $122.4 \pm 14.67$ & $118.6 \pm 11.56$ & $116.2 \pm 11.92$ & $111.4 \pm 11.95$ \\
\hline Alkaline phosphatase. U/1 & $367.7 \pm 87.16$ & $378.0 \pm 86.13$ & $387.0 \pm 81.15$ & $393.0 \pm 83.15$ \\
\hline Urea. mmol/1 & $3.78 \pm 0.39$ & $3.74 \pm 0.36$ & $3.74 \pm 0.38$ & $3.77 \pm 0.35$ \\
\hline Creatinine. mcm/1 & $75.1 \pm 8.38$ & $75.8 \pm 8.34$ & $75.1 \pm 8.36$ & $75.3 \pm 8.31$ \\
\hline Glucose. mol/1 & $5.46 \pm 0.29$ & $5.48 \pm 0.25$ & $5.45 \pm 0.28$ & $5.43 \pm 0.25$ \\
\hline Total bilirubin. mcm/1 & $12.6 \pm 1.8$ & $12.7 \pm 1.1$ & $12.5 \pm 1.7$ & $12.0 \pm 1.3$ \\
\hline Straight bilirubin. $\mathrm{mmol} / 1$ & $8.4 \pm 3.8$ & $8.5 \pm 3.7$ & $8.3 \pm 3.9$ & $8.9 \pm 3 . .4$ \\
\hline
\end{tabular}




\begin{tabular}{|l|c|c|c|c|}
\hline \multicolumn{5}{|c|}{ 10 days after the last injection } \\
\hline \multirow{2}{*}{ Indicators } & Animal group. dose. mg / kg \\
\cline { 2 - 5 } & Control & $\mathbf{1 / 1 0}$ from LD50 & $\mathbf{1 / 2 0}$ from LD50 & $\mathbf{1 / 5 0}$ from LD50 \\
\hline Crude protein. g/l & $69.1 \pm 2.18$ & $63.6 \pm 2.34$ & $64.6 \pm 2.17$ & $62.4 \pm 2.16$ \\
\hline AsAT. U/1 & $162.3 \pm 24.6$ & $167.9 \pm 27.4$ & $168.3 \pm 25.6$ & $168.6 \pm 23.8$ \\
\hline AlAT. U/1 & $117.8 \pm 11.84$ & $115.4 \pm 11.81$ & $119.5 \pm 11.51$ & $116.7 \pm 11.64$ \\
\hline Alkaline phosphatase U/1 & $367.6 \pm 83.16$ & $379.7 \pm 83.19$ & $397.0 \pm 87.15$ & $396.2 \pm 85.17$ \\
\hline Urea. mmol/1 & $3.73 \pm 0.37$ & $3.75 \pm 0.39$ & $3.78 \pm 0.37$ & $3.75 \pm 0.31$ \\
\hline Creatinine. mcm/1 & $75.9 \pm 8.36$ & $75.4 \pm 8.38$ & $73.7 \pm 8.36$ & $75.5 \pm 8.67$ \\
\hline Glucose. mol/1 & $5.44 \pm 0.21$ & $5.41 \pm 0.28$ & $5.46 \pm 0.29$ & $5.45 \pm 0.21$ \\
\hline Total bilirubin. microns/1 & $12.3 \pm 1.8$ & $12.9 \pm 1.6$ & $12.4 \pm 1.7$ & $12.7 \pm 1.6$ \\
\hline Straight bilirubin. mmol/1 & $8.5 \pm 3.8$ & $8.7 \pm 3.1$ & $8.2 \pm 3.7$ & $8.9 \pm 3.6$ \\
\hline
\end{tabular}

Where: *- $p \leq 0.05$ - the difference is statistically significant in comparison with the indicators of the control group.

The data of rat necropsy were generalized for all groups of the studied animals, since the results of macroscopic examination of the studied organs showed no differences between the groups. All the rats had the correct physique. External examination revealed no discharge from the natural orifices. The hair is shiny, neat-looking, and there are no foci of baldness. The teeth are preserved. The visible mucous membranes are pale and shiny. When palpation of the mammary glands, there were no seals, no discharge from the nipples. Sexual organs of males of correct development. There was no deformity or swelling of the limbs. The skin at the site of application of the drugs did not present any changes. Infiltrates, irritation, or tissue necrosis were not observed. Skin of normal color, without signs of irritation.

When autopsy the thoracic and abdominal cavities, the anatomically correct location of internal organs was noted. The appearance and condition of the organs had the same picture in animals of all groups. The serous membranes of the cavities had a bright pink color and a smooth and shiny surface. The size and shape of the heart did not change. The heart is not enlarged, the pericardium and epicardium are smooth and shiny. The heart valves are thin, smooth, and shiny. The diameter of the aorta is not changed. The heart muscle has a uniform brownish color, moderate density to the touch. Lungs are without pathological changes, normal lobular structure was determined, filled with air, no seals were found on palpation, pale pink color. The lumen of the trachea and large bronchi is not changed, the mucous membrane is shiny, smooth, and pale in color. The liver is not enlarged, the capsule is smooth, shiny, dark red color, full-blooded on the cut, moderately dense. The spleen is elongated, dark cherry color, moderate density to the touch. The surface of the organ is smooth, the capsule is thin. When cut, the gray follicles are clearly visible on a dark red background. Thymus in the form of a triangle, whitish color, moderately dense consistency, standard sizes. The size and shape of kidneys are not changed, they are located symmetrically. The surface is brown, smooth, the fibrous capsule is thin, shiny, easily removed, thecortical and medullary substance are clearly distinguishable on the incision. The consistency of the organ is moderately dense. The adrenal glands are rounded, pale yellow in color, with a smooth surface, elastic. Dark-colored medullary matter is clearly visible on the section. The esophageal mucosa is shiny, smooth, and pale in color. The stomach is of standard size and shape, filled with food content. The mucous membrane of the non-gelatinous part of the stomach is folded, pink, and shiny. The mucous membrane of the small intestine is pale pink, shiny, smooth. The mucous membrane of the colon is grayish, shiny, smooth. The testes are oblong in shape, pale gray in color, and of a testy consistency. The body of the uterus is of standard size and shape, of normal density. The horns of the uterus are thin, the mucous membrane is shiny and pale. Ovaries are dark red in color, with a rough surface, moderate density to the touch. 
The results of morphometric analysis indicate that there are no statistically significant differences in the relative mass of internal organs in rats, with repeated use of drugs in the studied doses, compared with similar indicators in control animals (Table 5).

Table 5. Exosomal drug effect on internal organs mass of white Wistar rats.

\begin{tabular}{|c|c|c|c|c|}
\hline \multicolumn{5}{|c|}{24 hours after the last injection } \\
\hline \multirow{2}{*}{ Indicators } & \multicolumn{4}{|c|}{$\begin{array}{l}\text { Animal group. dose. } \mathrm{mg} / \mathrm{kg} \\
\end{array}$} \\
\hline & Control & 1/10 from LD50 & $1 / 20$ from LD50 & 1/50 from LD50 \\
\hline Liver & $25.3 \pm 0.68$ & $26.4 \pm 0.76$ & $26.4 \pm 0.71$ & $25.4 \pm 1.13$ \\
\hline Kidneys & $5.31 \pm 0.28$ & $5.51 \pm 0.15$ & $5.44 \pm 0.06$ & $5.63 \pm 0.15$ \\
\hline Lungs & $3.73 \pm 0.04$ & $3.88 \pm 0.15$ & $3.79 \pm 0.16$ & $3.78 \pm 0.25$ \\
\hline Spleen & $2.18 \pm 0.13$ & $2.23 \pm 0.08$ & $2.18 \pm 0.15$ & $2.13 \pm 0.16$ \\
\hline Heart & $2.84 \pm 0.07$ & $2.91 \pm 0.09$ & $2.93 \pm 0.05$ & $2.99 \pm 0.12$ \\
\hline \multicolumn{5}{|c|}{10 days after the last injection } \\
\hline \multirow{2}{*}{ Indicators } & \multicolumn{4}{|c|}{ Animal group. dose. $\mathrm{mg} / \mathrm{kg}$} \\
\hline & Control & 1/10 from LD50 & $1 / 20$ from LD50 & 1/50 from LD50 \\
\hline Liver & $29.5 \pm 0.63$ & $29.5 \pm 1.47$ & $28.2 \pm 1.67$ & $29.5 \pm 1.86$ \\
\hline Kidneys & $6.07 \pm 0.16$ & $6.05 \pm 0.44$ & $5.93 \pm 0.38$ & $5.83 \pm 0.47$ \\
\hline Lungs & $3.88 \pm 0.36$ & $3.77 \pm 0.45$ & $3.69 \pm 0.56$ & $3.59 \pm 0.65$ \\
\hline Spleen & $2.29 \pm 0.07$ & $2.13 \pm 0.26$ & $2.28 \pm 0.27$ & $2.27 \pm 0.34$ \\
\hline Heart & $3.04 \pm 0.26$ & $2.97 \pm 0.13$ & $2.92 \pm 0.33$ & $3.09 \pm 0.25$ \\
\hline
\end{tabular}

Where: *- $\mathrm{p} \leq 0.05$ - the difference is statistically significant in comparison with the indicators of the control group.

Thus, as a result of the study of subchronic oral toxicity of the developed drug based on exosomal particles in white rats of the Wistar line, it was found that its use intragastrically once a day for 90 days in doses of $1 / 10 ; 1 / 20$ and 1/50 of LD50 does not affect the behavioral reactions of animals and their General appearance. There is no negative effect on blood parameters and basic physiological functions of the body, there are no pathomorphological changes, which confirms the good tolerability of the drug.

\section{References}

1. N. Singh, A. Joshi, A. Pal Toor, G. Verma, Elsevier, 865-886 (2017) https://doi.org/10.1016/B978-0-323-46143-6.00027-0

2. Ohno Shin-ichiro, Kuroda Masahiko, Exosome-Mediated Targeted Delivery of miRNAs (2016) DOI:10.1007/978-1-4939-3753-0_19

3. F. Dreyer, A. Baur, Biogenesis and Functions of Exosomes and Extracellular Vesicles (2016) DOI:10.1007/978-1-4939-3753-0_15

4. N. Lu-Nguyen, M. Broadstock, R. Yáñez-Muñoz, Intrastriatal Delivery of IntegrationDeficient Lentiviral Vectors in a Rat Model of Parkinson's Disease (2016) 10.1007/978-1-4939-3753-0_13

5. A. Tan, J. Rajadas, A.M. Seifalian, Adv. Drug Deliver Rev. 65, 357-367 (2013)

6. J. Ren, W. He, L. Zheng, et al., Biomater. Sci. 4, 910-921 (2016)

7. L.A. Lane, X.M. Qian, A.M. Smith et. al., Annu Rev Phys Chem 66, 521-547 (2015)

8. M.C. Deregibus, F. Figliolini, S. D'Antico, et. al., Int. J. Mol. Med. 38, 1359-1366 (2016)

9. P. Calvo, C. Remuñán-López, J. Vila-Jato, M. Alonso, Journal of Applied Polymer Science 63, 125-132 (1997) 
10. K. Balagangadharan, International Journal of Biological Macromolecules 104(B), 1372-1382 (2017) doi.org/10.1016/j.ijbiomac.2016.12.046

11. M. Martínez-Martínez, European Journal of Pharmaceutics and Biopharmaceutics 136, 174-183 (2019) doi.org/10.1016/j.ejpb.2019.01.009

12. R. Shanmuganathan, International Journal of Biological Macromolecules 130, 727-736 (2019) doi.org/10.1016/j.ijbiomac.2019.02.060

13. T. Aminabhavi, Chitosan Based Biomaterials 2, 1-29 (2017) doi.org/10.1016/B978-008-100228-5.00001-8

14. J. Park, Nanomedicine: Nanotechnology, Biology and Medicine 13(6), 2015-2025 (2017) doi.org/10.1016/j.nano.2017.04.012

15. V. Engkagul, Nanomedicine: Nanotechnology, Biology and Medicine 13(8), 25232531 (2017) doi.org/10.1016/j.nano.2017.07.001

16. L. Du, Nanomedicine: Nanotechnology, Biology and Medicine 10(7), 1411-1420 (2014) doi.org/10.1016/j.nano.2014.04.001 